\title{
Chemical Contents of Hydroponic Plants
}

\author{
George Steven \\ Chemical Sciences Institute, London, United Kingdom \\ Email: george.s@gmail.com
}

\begin{abstract}
The world is increasingly sophisticated with technologies that help humans in the move, even in terms of compliance with food, but it is still in line with the development of technology that is the growing amount of human birth, so the lack of area for fulfillment in terms of planting of food crops, but the land is mostly reserved residential land, and even more we see this village, which is clearing land to grow crops other than basic foodstuffs, but only to enrich themselves. How do we as human beings who still want to meet the food needs facing arable land diminishing modern era is farming no longer have to use the soil of various methods of planting can be used for those who want to pursue her, one of which is farming hydroponic, hydroponics itself is a means farming without soil media when faced with the problems faced in the world in terms of food production, hydroponic gardening system offers a promising solution. In poor countries where soil or climate inhospitable to agriculture, hydroponics offers a means to grow crops with ease. also in areas where the soil has lost its nutrients or fertile land is hard to come by, hydroponics can be an ideal alternative to farming.

Keywords---hydroponic type, hydroponics plant material, meaning hydroponics, vegetables, water.
\end{abstract}

\section{Introduction}

As I explained above hydroponic plant is a plant that does not use soil media as the main ingredient, but in exchange for use of the water and some of his other additional media, in general hydroponic plant is usually a type of vegetables which grow age is not too long so plants (Atwood, 2017; Babu, 2016; Dai, 2006). Hydroponics is suitable to make our business area, especially our hobby farm but is limited by land is expensive (land) and a long time, hydroponic plant is present to overcome it all so we could garden anywhere and anytime can behind the house, as well as front of house for hydroponic crops other than as a business area can also be made as a home decoration because of its orderly in this article I will discuss a few points in between, the material is needed in starting a business, engineering hydroponics in general, some of the advantages and disadvantages her, and that last how this hydroponic crop prospects in the business world, the purpose of writing this article other than as a duty, also to open our insight that the world of agriculture was also made in the promising business area.

\section{Method}

In writing this article I take a lot from the internet, because of time constraints so it can not undergo direct research into the field, and if there are many errors in the writing request in understandable and hopefully this article useful.

\section{Discussion}

Hydroponics Latin hydro = water ponos = work is a method of farming without the use of soil media, but by using mineral nutrient solution or other material containing nutrients such as coconut fiber, mineral fiber, sand, broken bricks, sawdust, etc. others as a substitute for soil media (Ding et al., 2006; Fennell et al., 2015; Fox et al., 2004). Hydroponic plants can be done on a small scale at home as a hobby or on a large scale for commercial purposes, some plants are often grown hydroponically, are vegetables such as broccoli, cabbage, kailan, spinach, kale, 
tomatoes, onions, even strawberry, etc. Plants thus often become the primary choice of vegetarians who are very concerned the murder of a plant if there are living beings, mixed with chemical elements, environmental conservation, and afforestation (Giglioli-Guivarc'h, 2013; Gribble et al., 2009; Hazeltine et al., 2003).

Some of the ingredients are in need

Media hydroponics is good to have a neutral $\mathrm{pH}$ or between $5.5-6.5$. Also, the media should be porous and may retain moisture used media can be divided into two stages of plant growth by:

a. Media for the nursery or nurseries

The nursery can be used for media in the form of fine sand, husk charcoal or Rockwool. Fine sand is often used because it is easy to obtain and inexpensive, but less able to retain water and there are no nutrients in it. The medium used is a mixture of rice husk and sawdust or coconut coir dust (Hosseinzadeh et al., 2019; Kitaya et al., 2001; Klass, 1998).

b. Media for mature plants

Media for mature plants is almost the same as the media for seedlings, namely sand a bit rough, husk, rock wool and other media ideal is husk advantage is the cleanliness and sterility of the media is guaranteed free of dirt and organisms that can disrupt such as worms, fleas and so that can live in the sand. Rice husk is lighter yet more easily destroyed, its use can only be for the two-time usage rang husks can be purchased in stores or make your own farm (Kyaw et al., 2017; Levine et al., 2003; Nilsson et al., 2011).

Selection of seed is very important because crop productivity depends on the selected seed excellence check the seed package labels, namely the expiration date, and a growing percentage of seed purity. Selection of the commodity to be planted carefully calculated regarding pricing and marketing. Examples of exclusive vegetables that have a selling value above the average are recent tomato, cucumber japan, Parika, lettuce, melons, and others.

\section{Hydroponics Aquaculture Equipment}

Container seedlings can use plastic pots, small polybag, plastic tubs, seedling trays, or wooden boxes. Containergrown plants commonly used polybag $30-40 \mathrm{~cm}$ with enough holes to drain excess water when watering. Some of the ingredients are in need:

1. Tissue paper / wet newspapers to keep moisture

2. Sand sieve to sift the media for seedlings

3. Handsprayer for watering

4. spoon media mixer

5. Tweezers to collect the seeds from the container seedlings

6. Polybag size $5 \mathrm{~kg}$ for planting transplant

7. Flax yarn (as used builder) to tie the plant.

\section{Technique hydroponic}

There are two main techniques in hydroponic cultivation. The first to use the solution and the only one using the media. The method using a solution does not require harsh media for root growth, with just enough mineral nutrient solution. Examples of how the technique commonly used solution is a static solution technique and solution techniques flow (Song et al., 2011; Tako et al., 2001; Tikhomirov et al., 2003). As for the technique of media is dependent on the type of media used, can be a coconut fiber, mineral fiber, sand, broken bricks, sawdust, etc. as a substitute for soil media regardless of the technique used, most places bailout hydroponics made of plastic, but other materials can also be used including concrete tanks, glass, steel, wood and other solid materials the shelter must be kept away from light to prevent algae growth in the water that has been in the nutritious

\section{Excess plant hydroponic}

a. Saving land, hydroponics is suitable for places that only have limited land area live in cities certainly is in the house/apartment is also limited by the hydroponic method is for the sun to illuminate a limited area that we can still grow crops. One effort to utilize the land as optimal as possible is with hydroponics viticulture, namely hydroponics system to grow plants vertically. 
b. Freedom to choose one, hydroponics is suitably carried out in areas with poor soils. Because hydroponics does not use soil as a growing medium, then we can cultivate his land again, although its structure is sandy and barren.

c. Yields more, hydroponic produce lower yields than conventional methods (by land) in the same area.

d. Saving water, the more water-efficient hydroponics. Despite its name hydroponics but make no mistake, this method is even more water-efficient than conventional methods. In the conventional method, water is thrown to the ground to be absorbed and disappear. While the method of hydroponics, water is lost only water absorbed by plants and evaporated into the air and fewer in number.

e. Environmentally friendly, reduce the pollution of chemical substances into the soil. The hydroponic method does not use soil so it does not contaminate the soil and if forced to dispose of used any nutrients, hydroponic nutrient residue from almost nothing. In contrast to conventional methods which fertilizer residue will continue to accumulate in the soil and ultimately destroy the fertility of the soil.

\section{Disadvantages of hydroponic plants}

Nutrisi a special, special nutrients hydroponics and growing media are still hard to find. we should be searching and shopping online a couple of growing media such as hydration, Rockwool, and vermiculite are still imported, so a bit hard to find and the price is relatively more expensive (Toro-Labbé, 2006; Yongsheng et al., 2011).

Large capital required initial capital is relatively higher for hydroponics. Actually, if we are creative, hydroponics can be cheaper because we can take advantage of second-hand goods as a place to grow crops such as beverage bottles mineral, former jerry cans, Styrofoam place fruits, etc. But as soon as we want to create a bigger hydroponic garden, especially with running water system, of course, we need more complete equipment such as PVC / gutters, water pump, air pump, etc.

Treatment is difficult, hydroponics requires precision and patience. Changes in nutrient levels and $\mathrm{pH}$ greatly affects plant growth. If we are not careful and painstaking, will be immediately visible growth of plants that are not optimal.

\section{The outlook on the world of business}

Speaking about the efforts in the field of hydroponics is inseparable from Mr. Bob Sadino services which can be regarded as the first to introduce a system of hydroponic vegetable farming in Indonesia. Hydroponic vegetables introduced by Bob Sadino in supermarket Kemchick in about 90s, now hydroponics vegetable can be purchased at several well-known supermarket vegetable prices hydroponic fitted with a 4 to 5 times more expensive than ordinary vegetable prices in traditional markets. But because the hydroponic vegetables free from pesticide use, the process of planting until harvest that had high hygiene, fresher, and better packaging, so that the hydroponic vegetables are sold in some supermarkets are always quickly sold out. With the increasing public awareness of the vegetarian movement in addressing the issue of global warming, of course, demand for vegetables and fruits that come from environmentally friendly process would be a major demand in the list of their consumption, because of limited supplies, and a higher demand for vegetable types of hydroponic so business opportunities that are environmentally friendly is quite good for hailed by employers on a large scale, including opportunities to export to neighboring markets where demand is very high.

\section{Conclusion}

Hydroponics is a method of farming without the use of soil media, but by using mineral nutrient solution or other material containing nutrients such as coconut fiber, mineral fiber, sand, broken bricks, sawdust, and other media as a substitute for soil. There are two main techniques in hydroponic cultivation. The first to use the solution and the only one using the media. Some Important Factors To Look nutrient solution, media, and oxygen. Prospects using hydroponic cultivation technique is very good indeed if the technique is appropriate and properly executed, due to higher demand for high-quality vegetables that are among us today.

\section{Acknowledgment}

First of all I would like to thank God almighty one who has given me the time and health so this article can be resolved properly, and also I thank two parents who always gave a prayer to her child, who continues to provide 
guidance to me that this article can be resolved in a timely manner, and hopefully this article can be useful for everyone.

\section{References}

Atwood, J. L. (2017). Comprehensive supramolecular chemistry II. Elsevier.

Babu, S. (2016). Advances in chemical mechanical planarization (CMP). Woodhead Publishing.

Dai, L. (Ed.). (2006). Carbon nanotechnology: recent developments in chemistry, physics, materials science and device applications. Elsevier.

Ding, S., Liang, T., Zhang, C., Yan, J., \& Zhang, Z. (2006). RETRACTED: Effects of organic ligands on fractionation of rare earth elements (REEs) in hydroponic plants: An application to the determination of binding capacities by humic acid for modeling.

Fennell, P., \& Anthony, B. (Eds.). (2015). Calcium and chemical looping technology for Power Generation and Carbon Dioxide (CO2) Capture. Elsevier.

Fox, P. F., McSweeney, P. L., Cogan, T. M., \& Guinee, T. P. (Eds.). (2004). Cheese: Chemistry, Physics and Microbiology, Volume 1: General Aspects. Elsevier.

Giglioli-Guivarc'h, N. (2013). New Light on Alkaloid Biosynthesis and Future Prospects (Vol. 68). Academic Press.

Gribble, G. W., \& Joule, J. (Eds.). (2009). Progress in heterocyclic chemistry (Vol. 21). Elsevier.

Hazeltine, B., \& Bull, C. (Eds.). (2003). Field guide to appropriate technology. Elsevier.

Hosseinzadeh, S., Testai, D., BKheet, M., De Graeve, J., Roccaro, P., \& Van Hulle, S. (2019). Degradation of root exudates in closed hydroponic systems using UV/H2O2: Kinetic investigation, reaction pathways and cost analysis. Science of The Total Environment, 687, 479-487.

Kitaya, Y., Kawai, M., Tsuruyama, J., Takahashi, H., Tani, A., Goto, E., ... \& Kiyota, M. (2001). The effect of gravity on surface temperature and net photosynthetic rate of plant leaves. Advances in Space Research, 28(4), 659-664.

Klass, D. L. (1998). Biomass for renewable energy, fuels, and chemicals. Elsevier.

Kyaw, T. Y., \& Ng, A. K. (2017). Smart aquaponics system for urban farming. Energy Procedia, 143, 342-347.

Levine, L. H., Kagie, H. R., \& Garland, J. L. (2003). Biodegradation pathway of an anionic surfactant (Igepon TC42) during recycling waste water through plant hydroponics for advanced life support during long-duration space missions. Advances in Space Research, 31(1), 249-253.

Nilsson, A., Pettersson, L. G., \& Norskov, J. (Eds.). (2011). Chemical bonding at surfaces and interfaces. Elsevier.

Song, W., Chen, X., Yan, M., \& Deng, Q. (2011). Absorption and oxidation of arsenite by Pteris vittata roots and its kinetics. Procedia Engineering, 18, $72-77$.

Tako, Y., Arai, R., Otsubo, K., \& Nitta, K. (2001). Application of crop gas exchange and transpiration data obtained with CEEF to global change problem. Advances in Space Research, 27(9), 1541-1545.

Tikhomirov, A. A., Ushakova, S. A., Gribovskaya, I. A., Tirranen, L. S., Manukovsky, N. S., Zolotukhin, I. G., ... \& Lasseur, C. (2003). Light intensity and production parameters of phytocenoses cultivated on soil-like substrate under controled environment conditions. Advances in Space Research, 31(7), 1775-1780.

Toro-Labbé, A. (2006). Theoretical aspects of chemical reactivity (Vol. 19). Elsevier.

Yongsheng, W., Qihui, L., \& Qian, T. (2011). Effect of Pb on growth, accumulation and quality component of tea plant. Procedia Engineering, 18, 214-219. 